\title{
Justification of the construction of a self- propelled selection seeder with an intelligent seeding system
}

\author{
Alexander Lavrov ${ }^{1}$, Igor Smirnov ${ }^{1}$, and Maksim Litvinov ${ }^{1, *}$ \\ ${ }^{1}$ Federal Scientific Agroengineering Center VIM, 1-st Institutsky proezd, 5, Moscow, 109428, Russia.
}

\begin{abstract}
Aim of the state's programs is development of selection and seed production in Russia. It is required researching related to the creation of new intelligent technical systems which implemented in techniques for selection, in particular in a self-propelled selection seeder. It is proposed to develop an intelligent seed sowing technology and it will be realize on the basis of a self-propelled selection seeder.
\end{abstract}

\section{Introduction}

Nowdays standard kinematic transmission systems and drives are used in techniques and equipment for seeds selection. Mostly, foreign machinery and equipment occupied $60-80 \%$ of the market [1].

Manual seed supply systems and mechanical seed supply systems are used for sowing in the device of selection seeders, which leads to an increase of losses of seed material, an increase in the energy intensity and labor costs of the process. In addition, during the process of designing and developing of the selection machine and equipment, there don't account such important characteristics for the sowing process as: soil-climatic features of the rural areas, matching the speed of the seeder with the rotation speed of the sowing device, taking into account the changing skidding ratio.

We know seeders of continuous sowing with a chain drive from the driven wheel, a mechanical device for selecting the seed rate, sowing device. A drawback of known devices is a low seeding accuracy [2-4].

It should be noted that foreign machinery with an automated seed supply systems and sowing system are used [5], but intellectual software does not consider the natural and climatic features of the Russian Federation and it is directly based and linked to the main program code of developers.

All of the above listed are significantly reduced the efficiency of the seeding process and, as a consequence, the productivity of the farm [6].

The solution of this problem is development of domestic innovative seeding techniques with using the technology of intellectual seeding of seed.

The closest seeder in terms of the technical nature is the sowing unit of the Wintersteiger Plotseed S seeder which is selected as a prototype. The disadvantages of the

* Corresponding author: litvvinov.max@yandex.ru 
known device are low seeding accuracy due to poor adhesion to the soil, inertness of the mechanical drive, lack of feedback of the sowing device drive.

The technical purpose of the invention is increasing the accuracy of sowing crops seeds by eliminating the rigid coupling of the driven wheel with the seeding device and replacing it with an electronic one, as well as reducing the error in the sowing rate due to slipping of the wheels, due to the inertia of the mechanical drive and the absence of monitoring devices .

The invented technical problem of the invention is solved by the adjusting the seed rate of continuous seeding including the seeding machine with its drive, the operator panel, telemetric sensors placed on the driven wheel according to the invention. It is equipped with an electronic control unit on the seeder and the slit optical sensor in the seeding system of the sowing device, connected by feedback. The drive of the sowing apparatus is made from a stepper motor which controlled by the electronic unit.

Synchronization of rotation of the sowing apparatus and real speed is carried out due to the intellectual drive developed by the FGBAC FNAC VIM by a group of researchers. Figure 1 shows the layout of the seed drill in the inter-axis space of the self-propelled chassis of Agromash $30 \mathrm{SS}$.

The aims of the research are placing a mounted seeder in the inter-axis space of the selfpropelled chassis and replacing the mechanical drive with the possibility to correlate the seeding rate for different crops, soils, climatic conditions.

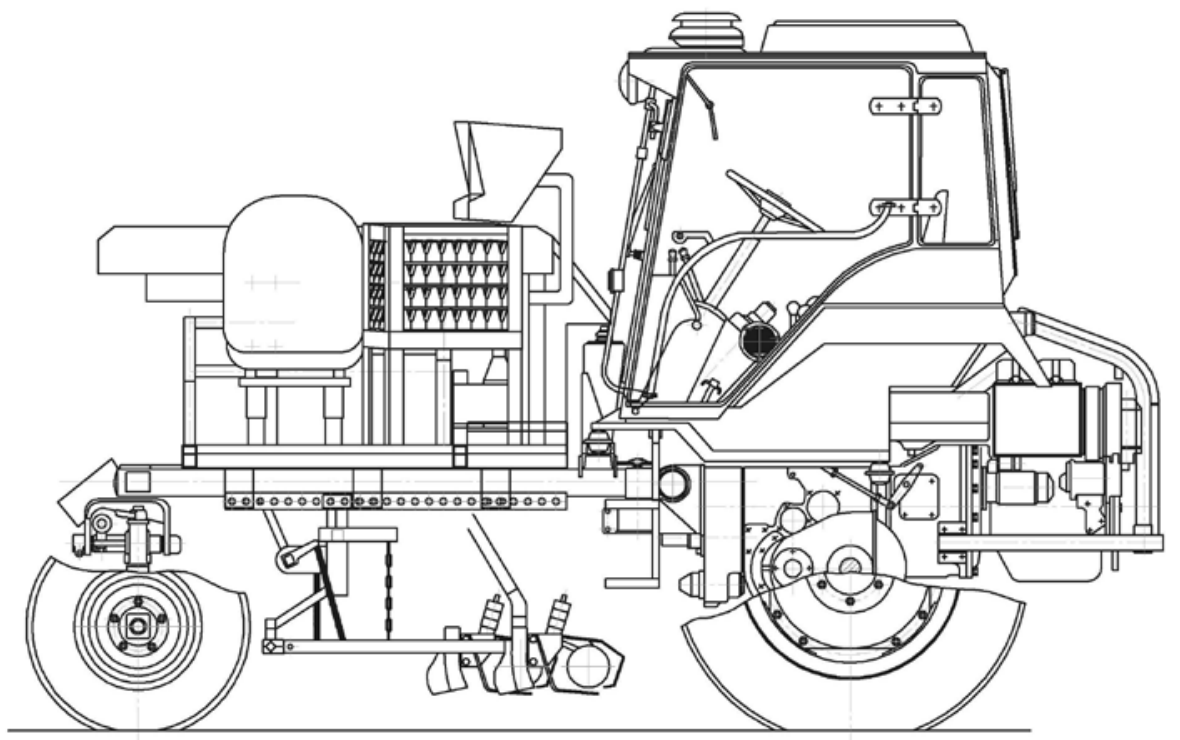

Fig. 1. General view of a self-propelled selection seeder.

\section{Materials and methods}

\section{$\underline{\text { Seeder }}$}

The machine for research was the Rowseed S seeder (WINTERSTEIGER). It is intended for the continuous sowing of crops, legumes and cereals in the plots of the second stage of selection. The factory provided the drive of the sowing device from an additional wheel and changed the seeding rate for different crops by permuting the sprocket gears. 
We used the Global Sow Control System (GSC) for this seeder, which allows to configure the parameters of the plots and the sowing device. This system controls the power supply to the electric motors of the cassette feeding mechanism during ordinary seeding, and also it notifies with an audible signal if the cassettes are empty.

Table 1 shows the technical characteristics of this seeder.

Table 1. The main characteristics and parameters of a seeder for continuous sowing of cereals (WINTERSTEIGER Rowseed S, Austria)

\begin{tabular}{|l|l|}
\hline Control System & System Global Seed Control (GSC). \\
\hline Drive & From the wheel with a telemetric sensor \\
\hline Weight, $\mathrm{kg}$ & 400 \\
\hline Amount of plots & 6 \\
\hline Type of furrow-opener & Two-dick NODET \\
\hline Width of grip, $\mathrm{m}$ & 1,25 \\
\hline
\end{tabular}

\section{Self-propelled chassis}

The energy machine was the self-propelled chassis of the Agromash $30 \mathrm{SS}$ (manufactured by VLADIMIR MOTOR-TRAKTORNY PLANT LLC), which is used to aggregate to the seeder. The self-propelled chassis VTZ-30SH and its modifications are universal four-wheeled tractors of frame construction. On this self-propelled chassis diesel and power transmission are located at the rear part, and the front part is an open tubular frame with the cargo platform.

The self-propelled chassis VTZ-30SH and its modifications are intended for using as a universal transporting machine and also as a base for mounting on the different machinery frames (mounting machine, equipment and working bodies) for producing special works in agriculture, public utilities and industry.

The installation of the equipment on the chassis frame is provided a good overview of the rows and the working bodies of the equipment, however, this chassis can not synchronize the working bodies of the attachments with the speed of movement.

The main technical characteristics of the self-propelled chassis (Agromash 30SH, Russia, Vladimir) are presented in Table 2.

Table 2. The main characteristics of the self-propelled chassis (VMTZ Agromash 30SH, Russia)

\begin{tabular}{|l|l|}
\hline Type & $\begin{array}{c}\text { Self-propelled, universal wheel with } \\
\text { reverse }\end{array}$ \\
\hline Traction class & 0,6 \\
\hline Weight, $\mathrm{kg}$ & 2460 \\
\hline Engine operating power, h.p. & 30 \\
\hline Row, mm & 1424 \\
\hline Overall dimensions: $\mathrm{l}^{*} \mathrm{~W} * \mathrm{~h}, \mathrm{~mm}$ & $4205 * 1630 * 2632$ \\
\hline Frame, mm & 2510 \\
\hline Agrotechnical clearance, $\mathrm{mm}$ & 450 \\
\hline
\end{tabular}

\section{Device for intellectual sowing}

It was developed an intelligent seed sowing device to adapted the seeder to a selfpropelled chassis, (figure 2, table 3 ), which included a seeding machine with its drive, an operator panel, telemetric sensors placed on the driven wheel and a seed rate control solenoid. The device is made of a stepper motor with a microcontroller and intelligent seeding program. 


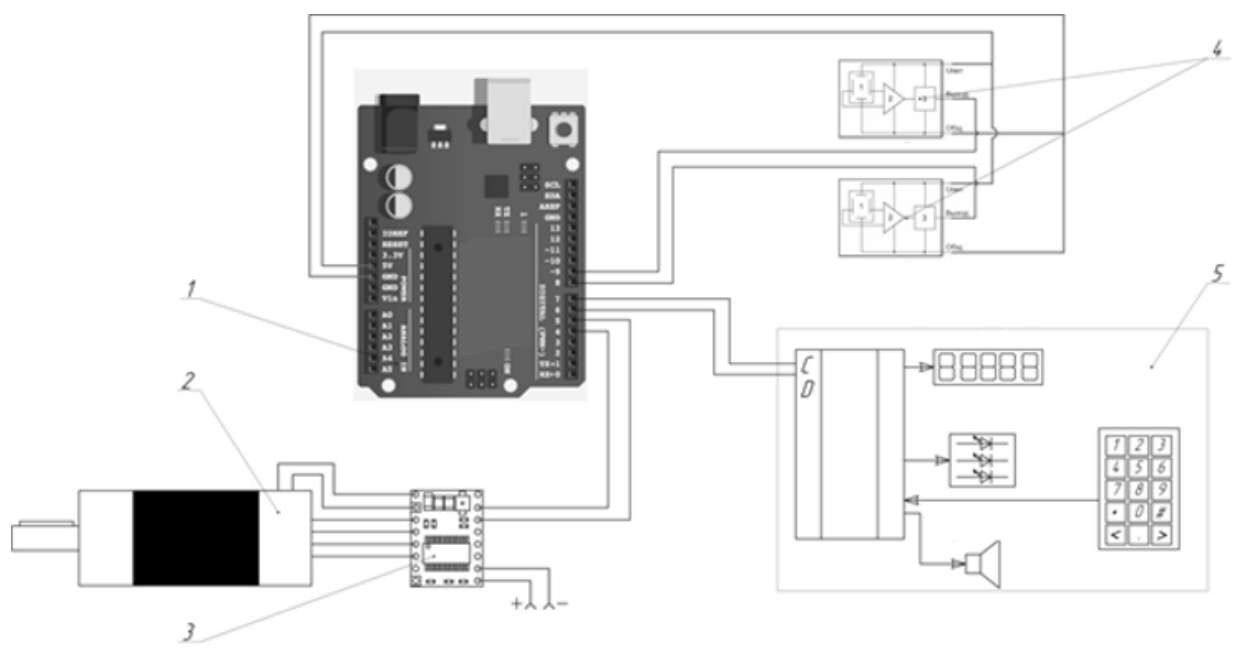

Fig. 2. Schematic diagram of an intelligent seeding device.

Table 3. Technical characteristics of the intelligent seeding device

\begin{tabular}{|l|l|}
\hline Type and model of the engine & Step. FL86STH118 \\
\hline Power consumption, $\mathrm{W}$ & 210 \\
\hline Maximum torque, $\mathrm{N}^{*} \mathrm{~m}$ & 8,7 \\
\hline Weight, $\mathrm{kg}$ & 3,8 \\
\hline Controller Model & Arduina Mega 2560 \\
\hline Driver Model Модель драйвера & SMSD-4.2RS-485 \\
\hline
\end{tabular}

The system of intelligent sowing works in such way. Halls telemetric sensors 4 are installed on the driven wheels of a seeder or a tractor to obtain telemetry data. The operator sets the seed rate at the operator's console 5. Hall sensors 4 remove the original signal from the seed drill during moving of the seeder. Microcontroller 1 processes the received signal, excludes wheel slip, generates a control signal for driver 3. Driver 3, in turn, drives stepper motor 2, which rotates the shaft of the sowing apparatus. Based on the data received from the sensors 4, the microcontroller 1 corrects the frequency of the output pulses. Installation of sensors 4 is necessary to reduce the error of the length of the plots due to wheel slippage. After correcting the data, the microcontroller 1 generates the output pulses in accordance with a predetermined program and sends them to the controller 3 of the stepper motor 2 . The stepper motor 2 rotates the shaft of the seeder.

To determine the uniformity of seed distribution along the length of the row, investigations of the sowing apparatus were carried out in accordance with GOST 313952007 (Tractor seeders, test methods).

\section{Results and discussions}

We conducted laboratory and field tests for evaluating the efficiency of the self-propelled selection seeder. During the tests, the following process parameters were evaluated: uniformity of seeding, uniformity of depth of embedding in the longitudinal, transverse direction.

Qualitative performance of the seeder is determined by sowing plots of $10 \mathrm{~m}$ in length. The number of plants is shown in Table 4 on one running meter. 
Table 4. Amount of plants in a $10 \mathrm{~m}$ length plot

\begin{tabular}{|c|c|c|c|c|c|c|c|}
\hline \multirow[t]{2}{*}{ Indicators } & \multicolumn{6}{|c|}{ Number of sowing device } & \multirow[t]{2}{*}{ Average } \\
\hline & 1 & 2 & 3 & 4 & 5 & 6 & \\
\hline $\begin{array}{l}\text { Amount of } \\
\text { plants on } 1 \\
\text { running meter } \\
\text { of row: }\end{array}$ & & & & & & & \\
\hline $\begin{array}{c}- \text { in the } \\
\text { beginning }\end{array}$ & 21 & 22 & 23 & 21 & 22 & 20 & 21,5 \\
\hline $\begin{array}{l}\text {-in the } \\
\text { middle }\end{array}$ & 22 & 20 & 19 & 22 & 22 & 20 & 20,8 \\
\hline -at the end & 20 & 21 & 22 & 19 & 19 & 19 & 20,0 \\
\hline $\begin{array}{l}\text { Average } \\
\text { quadratic } \\
\text { deviation }\end{array}$ & 1 & 1 & 2,08 & 1,52 & 1,73 & 0,57 & 0,75 \\
\hline $\begin{array}{l}\text { Coefficient of } \\
\text { variation, } \%\end{array}$ & 4,7 & 4,7 & 9,7 & 7,3 & 8,2 & 2,9 & 3,6 \\
\hline
\end{tabular}

Analysis of the obtained data shows that the design of the seeder ensures uniform sowing of the seeds of the flask along length of the row. The mean square deviation along the length of the row does not exceed 0.75 pieces, and the coefficient of variation is $3.6 \%$, which corresponds to the agrotechnical requirements, when the seeds are distributed in rows with a seed spacing of $5 \mathrm{~cm}$.

The depth of seeding by different sowing machines along the row length is shown in Table 5 .

Table 5. Depth of seeding by a self-propelled selection seeder

\begin{tabular}{|c|c|c|c|c|c|c|c|}
\hline \multirow[t]{2}{*}{ Indicators } & \multicolumn{6}{|c|}{ Number of sowing device } & \multirow[t]{2}{*}{ Average } \\
\hline & 1 & 2 & 3 & 4 & 5 & 6 & \\
\hline $\begin{array}{l}\text { Depth of } \\
\text { seeding on } 1 \\
\text { running meter } \\
\text { of row: }\end{array}$ & & & & & & & \\
\hline $\begin{array}{l}\text { - in the } \\
\text { beginning }\end{array}$ & 5,9 & 7,1 & 5,9 & 6,4 & 7,6 & 5,6 & 6,4 \\
\hline -in the middle & 6,1 & 6,9 & 7,5 & 5,4 & 6,6 & 5,9 & 6,4 \\
\hline -at the end & 5,3 & 6,1 & 7,3 & 7,6 & 6,7 & 4,9 & 6,3 \\
\hline $\begin{array}{l}\text { Average } \\
\text { quadratic } \\
\text { deviation }\end{array}$ & & & & & & & \\
\hline $\begin{array}{l}\text { Coefficient of } \\
\text { variation, } \%\end{array}$ & $2^{7,2}$ & $\begin{array}{l}7,9 \\
0\end{array}$ & $\begin{array}{l}12,6 \\
3\end{array}$ & $\begin{array}{l}17,0 \\
3\end{array}$ & $\begin{array}{l}7,9 \\
1\end{array}$ & $9^{9,3}$ & 0,84 \\
\hline
\end{tabular}

Analysis of the obtained data shows that the seed drill provides an even depth of seeding. It varies from $4.9 \mathrm{~cm}$ to $7.6 \mathrm{~cm}$, which corresponds to agrotechnical requirements.

\section{Conclusions}

As a result of the carried out researches it is established that a self-propelled selection seeder with an intelligent drive of the sowing apparatus ensures a high-quality and 
consistent seed sowing along the entire length of the plot. In addition, the location of the seeder in the inter-axis space of the self-propelled chassis allows reducing overall energy costs and increasing the changeable capacity.

\section{Reference}

1. Kryazhkov. V.M., Gojaev Z.A., Shevtsov V.G., Lavrov A.V., Park of tractors: state and direction of development. Rural mechanizer. № 9, pp 3-5. (2015).

2. Systems of machines for the integrated mechanization of agricultural production for 1986 -1995, Part 1, Plant growing., pp. 850-856. (1988)

3. Aniskin V.I., Kosmovsky Yu.A., Nekipelov Yu.F. Peday N.P., Polyakov A.G., Machines for breeding in fielding, Moscow: VIM, 204 p. (2001).

4. Aniskin V.I., Nekipelov Yu.F., Mechanization of experimental works in selection, variety testing and primary seed farming of cereals and leguminous crops, Moscow: VIM, 200 p. (2004)

5. H.W. Griepentrog, P.T. Skou J.F., Soriano B.S., Blackmore, Design of a Seeder to Achieve Highly Uniform Sowing Patterns, 5th 5th International Conference on Precision Agriculture, Uppsala, Sweden, 9th-12th June 2005, pp. 675 - 682.

6. Moskovskiy M.N., Synthesis of system solutions for the technological process of obtaining seeds on the basis of structural-functional modeling, dis. dok. tech. sciences., Rostov-on-Don, Kuban State Agricultural University. I.T. Trubilina, 290 p. (2017) 